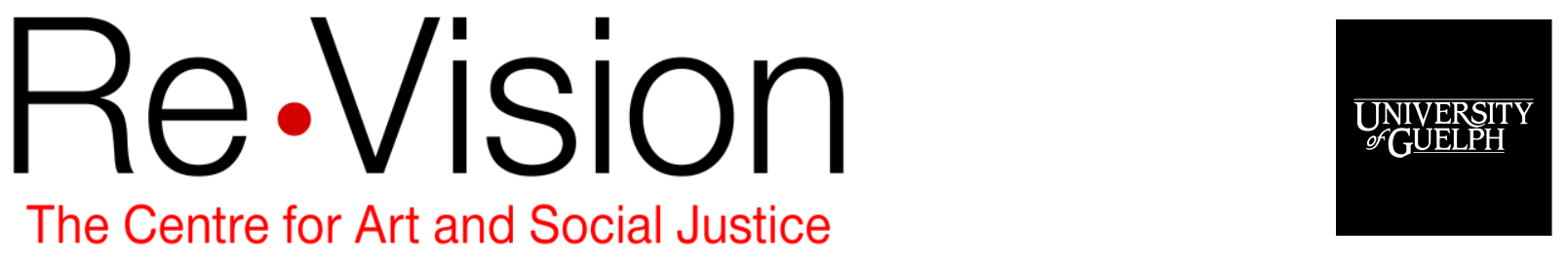

\title{
Mapping the circulation of fat hatred
}

Jen Rinaldi

University of Ontario Institute of Technology

Carla Rice

University of Guelph

Crystal Kotow

York University

Emma Lind

Okanagan College

This is an Accepted Manuscript of an article published by Taylor \& Francis in Fat Studies: An Interdisciplinary Journal of Body Weight and Society on April 11, 2019, available online:

https://www.tandfonline.com/doi/full/10.1080/21604851.2019.1592949

\section{Recommended citation:}

Rinaldi, J., Rice, C., Kotow, C., Lind, E. (2019). Mapping the circulation of fat hatred. Fat Studies: An Interdisciplinary Journal of Body Weight and Society. https://doi.org/10.1080/21604851.2019.1592949 


\section{MAPPING THE CIRCULATION OF FAT HATRED}

We draw from affect theory and intersectionality-as-assemblage theory to conceptualize fatmisia as a complex affective force. The term fatmisia-the misia derived from the Greek misos, meaning hatred, dislike, or contempt-refers to hatred of fat, fatness, and fat persons. The strength of the term-and its capacity to encompass, not equate to, fatphobia or fear of fat-positions feelings about and treatment of fat persons on a register comparable to, for example, misogyny or hatred of women. Unwelcome interactions with fat persons encompass concern, judgment, dread, disdain, revulsion, and violence. These expressions share in common how they operate relationally in the spaces between bodies-how they give shape to and produce in bodies orientations, directions, and movements toward and away from other bodies. In line with queer affect theorist Sara Ahmed's (2004) theorizing of emotion, we are interested in how fat hatred circulates as an affective economy: how it flows across, attaches to, and comes to define or value different bodies.

We analyze interview data compiled for the research project Through Thick \& Thin. For this project, we interviewed queer women and trans folk who carry a range of intersecting identity markers and express shifting locations in social relations. A majority of participants identified as being currently fat or as having been fat. They shared their experiences of how reactions that we coded under the rubric of fat hatred manifested in healthcare contexts, on transit, and while exercising. The data yielded insight into how fat hatred obstructs access to public participation, resources, and services, by rendering public space and social exchanges uncomfortable, unwelcoming, unsafe, and inaccessible. We use this data to surface the constellation of feelings that adhere to subjects, objects, and discourses, which become instruments of 
fatmisia, and how those instruments operate relationally in the space between bodies with the object of erasing or expunging fat life.

\section{HOW FATMISIA WORKS}

To make sense of hatred as affect, we turn to Ahmed. In The Cultural Politics of Emotion, Ahmed (2004) theorizes emotion, a complex and contested concept in the affect theory field. She characterizes emotions as intentional, insofar as "they are 'about' something: they involve a direction or orientation towards an object" (p. 7). Ahmed argues that emotion as affective force orients, mobilizes, and moves those who feel it in the direction of the emotion's object. So rather than materializing within the boundaries of the human body, emotion "arises in the midst of an in-between-ness" (Seigworth \& Gregg, 2010, p. 1). This affect circulates and transmits, rippling along and pounding against the surfaces of subjectivities, and it is through this relationality that subjectivities are bound together, and defined against one another. In Ahmed's words: "It is through emotions, or how we respond to objects and others, that surfaces or boundaries are made" (2004, p. 10). She invokes the metaphor of an economy: a marketplace wherein currencies of hatred and happiness are distributed and invested (Zembylas, 2007).

In affective economies, hatred may not be one singular emotion, but rather a constellation of negative emotions including disdain, fear, and disgust. What these emotions hold in common is how they are oriented, and what they do. In "The Organization of Hate," Ahmed (2001) describes the movement of hatred, suggesting that the "sideways, forwards and backwards movement of emotions such as hate is not contained within the contours of a subject, but moves across or between subjects, objects, signs and others" (p. 348). Hate organizes communities and ideologies—online comment boards, political constituencies, peer groups, communities of experts-by moving through and herding together subjects with a common collection of negative orientations, or positionings defined by their 'againstness.' But hatred also calibrates relationships between subject and object, hater and hated, by firming up or walling off their boundaries within, between, 
and around bodies. The intention of hatred that binds the hater to the hated is annihilation (Opotow \& McClelland, 2007).

We present accounts of interview participants who have experienced hatred directed at their fatness in assemblage. Using intersectionality-as-assemblage theory (Rice et al., forthcoming), we explore instances where participants describe becoming objects of hate owing to fatness alongside other aspects to their embodied being. Following queer theorist Jasbir Puar $(2007,2012)$, we reframe these entanglements through the Deleuzian concept of "assemblage" (Deleuze \& Guattari, 1988), a term referring to a complex and dynamic arrangement of ideas and material forms that emerge, stabilize, and dissipate through confrontation with knowledges, identifications, and structural conditions. The framing of intersectional identity as an assemblage thus enables us to account for how hatred flows through subjects and relationships. We map a range of expressions or instruments of hatred_how fat hatred has been distributed-in an effort to show that "there are different workings of hate feelings" (Zembylas, 2007, p. 187). Our interest is in exploring how antifat sentiment circulates, entangles with other expressions of hatred, and materializes in/as the contours shaping embodied subjects and social relations. We analyze people who experience fatmisia to argue that hatred leaves impressions upon them, and shapes their relationships by generating in them shame, isolation, and anxiety.

\section{MAPPING FATMISIA: DATA ANALYSIS}

Through Thick \& Thin engaged with how queer folk negotiate, are affected by, and resist body image ideals and body management expectations. We conducted in-depth semi-structured interviews with 24 participants residing in Ontario Canada, whom we recruited using purposive sampling methods. Our data collection methods were intentionally intersectional, designed to ensure that the range of experience captured was diverse. Given the fluidity of bodies and the instability of categories assigned to them, we resisted classifying participants according to weight or size; however, almost all (21) described themselves as being 
or having been fat. Their chosen size descriptors—ranging from "fat," "big girl," "thick," "chubby," "superfat," "considered big in Asia," to "depending," "unsure, curvy, bigger than typical," and "fat but sometimes pass"begin to unravel how "fat" might be imagined as a relational construct that de/materializes through specific assemblages of bodies, affects, and worlds. Over half also described living with "mental health" issues, which they related to the everyday hostilities directed at them. Finally, almost half identified as racialized or Indigenous using descriptors such as "person of colour," "mixed," "Indigenous in India," "Indigenous history, Mayan," "Black," "Asian," and "white," demonstrating how race and indigeneity likewise are relational constructs that stick and dissolve across bodies, time, and place. While space limitations prevented us from selecting quotes for this article from all participants, we endeavoured to ensure that our findings reflect diversity.

We transcribed and coded interviews using thematic methods (Braun \& Clarke, 2006) informed by intersectionality-as-assemblage and affect theory. We attended to moments of affective intensity, wherein participants describe becoming objects of disgust, fear, and disdain. Building on the paradigm-shifting work of Kimberlé Crenshaw (1989) on intersectionality, we mobilized the work of scholars who have brought intersectionality into conversation with non-essentialist and dynamic frameworks, notably feminist affect and assemblage theory (Puar, 2012). We analyzed participants' descriptions of viscerally charged encounters and embodied experiences of hatred as 'intersectional assemblages' or 'affective embodiments'-as emotionally charged, fleshy entanglements of fatness with other embodied differences that could not be split off into separate parts. Through thematic coding and data analysis using affect and assemblage theory, we identified and organized participants' descriptions of hateful experiences into patterns. This allowed us to map the spaces of fatmisia, or the relational spaces where hatred as an affective force was most powerfully felt: in healthcare contexts, on transit, and while exercising.

\section{HEALTHCARE}


According to Through Thick \& Thin interview participants, fat hatred bubbles up in the patientpractitioner encounter-sometimes subtly, sometimes surreptitiously, sometimes absent words, yet interviewees are clear in their recognition of these happenings as hate incidents. One common instrument of fat hatred to surface in the interviews is presumption, such as when healthcare practitioners assumed participants had or would eventually have diabetes. Leigh, a fat queer cis woman of colour with a degenerative physical disability, describes a pre-op surgical consultation with a medical student she had just met: "I [asked] 'If I do go through with the surgery, is there anything I need to do to prepare for it?' And he was like, 'Well, you could start by losing some weight and not getting diabetes." The student's response contradicted her surgical team's prior warning that exercising would aggravate her condition in the lead-up to surgery. In another example, Harper, a lesbian cis-femme woman of colour who identifies as plus size and has diabetes, describes an encounter with her endocrinologist's assistant:

"I don't know him from John, he has no record of my medical experiences. Anything like that. And his first suggestion...on how to correct my diabetes is to get a waist band surgery for my stomach. And I'm just like, you don't even know me! You don't know—I'm not obese to the point where I even need to have that done! It's not safe for me to do that! Before you even give me a chance to even look into losing weight the natural way or to try different things, you're suggesting that I go on weight-loss surgery."

Medical practitioners presented to our participants prognoses and recommendations as expressions of concern for their patient or the exercise of their responsibility. Nevertheless, interviewees are quick and firm to juxtapose medical advice against their own medical record: the absence of a diabetes diagnosis, the existing diagnosis of polycystic ovarian syndrome, the necessity of taking medication with weight-gaining side effects, the inability to exercise safely, not qualifying for the recommended surgery. For participants, this common theme of cautioning against diabetes and advocating diabetes prevention via surgical means does 
not stem from-and even contradicts-their records. The frequency with which advice was given absent evidence was relentless. In Harper's words:

\begin{abstract}
"It doesn't matter what kind of doctor. It doesn't matter what healthcare professional. Every single time a healthcare professional sees me, there's assumptions about my body. There's assumptions that I don't work out, there's assumptions that all I do is eat. There's assumptions that all I do is overeating when I'm usually under eating. Um, and all of these negative stereotypes that get attached to my body."
\end{abstract}

Harper is describing the accumulative force of medical assumption. Assumptions about her body get attached, or stick to her. The stickiness of affect (Ahmed, 2004; Guattari, 1996; Massumi, 2002) is one method of circulation, one way in which affect moves. Further, Harper's and Leigh's fatness entangles with brownness in the larger context of a cultural and medical imaginary that racializes fatness and conflates it with diabetes in Indigenous and racialized groups (Fee, 2006; Poudrier, 2007; Rail \& Jette, 2015). This alone might embolden healthcare practitioners to make markedly authoritative statements in clinical interactions with racialized persons, statements that impress pathological otherness as natural fact onto fat brown individual and collective bodies. The presumptions that they slip into their encounters with these racialized patients reveal their intention-to expunge fat (brown) life-and with force or repetition their intention latches onto the patient to leave lasting impressions.

Whereas presumption may be dressed in the guise of medical concern, shame as an amplified expression of hatred thrusts stereotype into a public forum and back onto the racialized fat body. Leigh recounts being publicly shamed in relation to the scale:

"I was like, 'I don't want to get weighed.' And [the nurse] was like, 'Well, it has to be done before we can give you the MRI.' I said, 'Fine, but I don't want you to tell me what I weigh. I 
don't want to look at the scale. I'm going to get on it backward.' ...They weighed me. And then he yelled my weight down the hall to the other MRI technicians."

Similarly, Melissa, a queer femme woman of colour who describes herself as voluptuous, was shamed in front of other patients at the close of a medical appointment:

"I remember he had opened the door already, so there were other patients in the other cubicles, and they could hear him. And he said to me, 'You need to lose weight and lower this cholesterol, unless you want to die from a heart attack.' And I was kind of taken aback, because we were done-the appointment was done. ...I said, 'You know, it's really inappropriate to say that to me.' And his response was, 'It's the truth."

In these examples, the words themselves carry impact, but an intentional component magnifying impact is the forum itself. Here space and audience are mobilized to direct affect by alienating the object of hate from the collective body. If an affective economy does not reside in any one person or thing but is instead dispersed (Ahmed, 2001), the space between and around objects can be organized in the service of this economy. If hatred is the emotion in circulation, its affective economy can be arranged to shut out the target of hate, or to throw them out of alignment with the larger body politic (Ahmed, 2010). Shaming renders the fat body hyper-visible (Gailey, 2014), in order to move the shamed to expunge their fat. This has particular resonance for fat racialized and Indigenous subjects who have a tenuous hold on belonging in a country founded on colonial violence and exclusionary immigration practices that still prioritize white settlers to be its most rightful citizens (Rinaldi et al., 2017).

Finally, another instrument of fat hatred that emerged in interview participants' medical encounters is the refusal to treat. Common across interviews was the medical practitioner's presumption that fat was the source of existing and future medical problems, and that weight-loss was the solution—despite overwhelming 
scientific evidence that long-term, permanent weight-loss is not possible for the vast majority of people who attempt it, and that strategies for achieving significant weight-loss are more detrimental to all aspects of health than simply remaining fat (Bacon \& Aphramor, 2011; Gaesser, 2009; Robison, 2015; Rothblum, 2018). The blanket weight-loss panacea-a product of healthist discourses born out of neoliberal notions of personal responsibility for health (Cooper, 2016)—pushed responsibility onto the patient, and thus absolved the practitioner of conducting examinations or prescribing treatment. Raine, a Black queer femme woman who is no longer fat, describes her experience seeking help from a doctor when in crisis:

\begin{abstract}
“There were days when I couldn't get out of my bed. There would be days I couldn't walk up stairs. There would be days that tears would be rolling down my face, because of how painful it was. ...And I was going into the doctor feeling quite hopeful about perhaps coming up with some ideas to just work with it, and was just provided with, 'You need to lose weight, that's pretty much it. Get out.' ... just have a feeling in my gut and in my soul, that this doctor, beyond telling me to lose weight, didn't have much more than that. No specific examples of health issues or reasons why or how to modify things, or a referral anywhere else. Just, you need to stop eating, was basically it."
\end{abstract}

Vaska, a fat queer white femme woman, offers her own example of alienation. Vaska recounts visiting her practitioner to inquire into a pregnancy test after going three weeks without results. Her doctor instead lectured her about her size: "She pushed back her clipboard and started launching into this speech about how I shouldn't be eating burgers and fries and fettuccini alfredo. And I said, 'I don't.' And she said, 'You must, look at you."' Vaska reflects on the impact of that conversation in the months that followed:

"In those weeks between blood tests, I had gotten pregnant, and by the time I found out, I was 11 weeks. And...had a really bad diet and was really depressed and was drinking like a fish and in a bad relationship, and I terminated the pregnancy. And I just thought like-my 
heart was broken. And I realized just how far this alienation from your own body can escalate when we've got these doctors as intermediaries between us and our bodies."

Raine and Vaska describe their doctors letting them down via indifference, or a refusal to engage. Interviewees' experiences align with Ahmed's characterization of rage against others that "surfaces as a body that stands apart or keeps its distance from others" $(2004$, p. 4). Fat hatred expressed through acts of distancing still strike a relation, for the affect carries through to impact the fat person. Acts of distancing convey the impression that the fat subject is not worth the effort.

Hate-oriented relationships also do distancing work when they are devoid of care. Drake, who identifies as a Two-Spirit butch woman but no longer identifies as fat, reflects on her experience in hospital for colon surgery, wherein she encountered a "lack of...human regard." Her friends supported her bathing, bathroom use, and bedsheet changes. Drake recalls:

"I had a terrible, terrible vomiting episode, and there was puke everywhere. All over everything. ...The maintenance person asked my friend if she would wipe up the vomit. On my food table. My friend said, 'No, I'm not going to do that,' which is the right answer. And they just left it there. They left the room. They mopped the floor and left the puke all over my food table-the table l'm supposed to eat off of."

Drake's experience reflects Sherene Razack's (2015) claim in the context of Indigenous medical care, that "indifference kills": "the pervasiveness of indifference...suggests a shared belief, an understanding that care would be wasted" (p. 112). In an interview with Deborah McPhail (2016), physician Barry Lavallee posits that stereotype-like Razack's invocation of waste-about Indigeneity and fatness coalesce in microaggressions, or violent everyday acts, that medical practitioners enact when they encounter this configuration of embodied difference. 


\section{IN TRANSIT}

Interview participants also identify public transit as a site where fat entangling with other forms of hatred surfaces. One way hate circulates on public transit is through the perceptions of other transit riders, whose words and gestures impress on participants the need to reduce the space their fat bodies occupy. When boarding transit, many participants describe having to decide between standing up and managing the associated physical pain, or sitting down and managing anxieties over other riders' discomfort with touching their fat. As Harper puts it:

"Because, in general, there's not any spaces for big women to be around and feel comfortable. I often observe it on the [transit system]... who's going to sit next to who, how's this going to maneuver. The looks that you're going to get if you sit in a spare seat and you're a bigger woman. Being conscious of that."

Vaska notes that while fat riders may choose to contort themselves, the motivation for doing so matters: "I was on the streetcar, and there was a guy sitting next to me, and I was trying my best to just balance on half of the seat. ...I didn't want to make him uncomfortable... and I didn't want to disgust him with my presence." Vaska's preoccupation with rousing disgust influences how she inhabits her body: by shrinking away as much as possible, by perching on the seat uncomfortably, she attempts to avoid becoming an object of the affective force of hate.

Some participants—particularly those with compounding identity markers-describe more overt acts of what they perceive to be fatmisia, but which may also entangle with sexism, racism, ableism, and homophobia. Leigh describes public transit as a "fraught space" for her as a fat disabled woman of colour. She recounts an experience riding a bus, where teenage boys laughed at her and threw various objects in her direction. She was left feeling the force of hatred organized into expressions of revulsion and acts of humiliation, and wondering what about her generated ridicule. Participants commonly discuss implicit 
expressions of hatred-inspecting looks, shaking heads, sucking teeth—and wonder whether these gestures are meant to call out their fatness, potentially in combination with other identity markers, among them class, race, sexuality, and gender expression. Anne, a 47-year-old bisexual, white cis woman who identifies as plus size, finds herself questioning whether she is reading others' body language correctly, and whether fat alongside other aspects of her self-presentation inspires hate from strangers on public transit:

"So, I'm not too sure what freaks people. I really don't. It could be the body size. It could be anything... moving slowly over this body. That's sort of-I don't know what it is. It could be everything. It could be one thing. Like I said, something in the eye. But I definitely feel it. I definitely feel something. Sometimes it's a shake of the head. I've actually had clicks of the tongue or sucking on the teeth."

These gestures-disapproving stares, disrespectful shakes, disdainful noises-become markers of "something," but Anne hesitates to name them as signs of fatmisia. Confusion enters the affective economy to accomplish a form of disavowal-a hegemonic denial that hatred is circulating. Both Leigh and Anne's hesitation or inability to name what inspired their experiences of hate makes sense within the framework of assemblage. Fatmisia in these cases assembles itself within misogyny, ableism, homophobia, and racism to produce feelings of alienation and confusion. Any assemblage of identity markers that moves a body away from the "master code" human template—white, heterosexual, able-bodied, fit, male (Rice, 2015)—marks a body as less human (Bahra, 2018), increasing risk of experiencing violence. Ahmed suggests that affective value accumulates via "circulation between objects and signs" (2004, p. 45), meaning that affects like hate grow stronger, perhaps more recognizable to the hated, the longer and more frequently they move around.

Whether explicit or not, participants describe moving through public space with the constant threat of becoming the object of fatmisia. This threat operates in relation to the physical design of public transit spaces, in which small seat sizes, narrow aisles, and truncated gaps between rows of seats impose strict 
boundaries that rub against the relative out-of-bound-ness of fat bodies. Here design becomes an instrument of hatred for bodies that exceed imposed boundaries. Participants describe attempting to avoid even greater exposure to the violence of fatmisia by resorting to physical contortion to ensure they do not move into other riders' seat spaces, in an attempt, to borrow from Ahmed (2017) and Puwar (2004), to avoid being perceived as "space invaders."

Observing which bodies are permitted to invade space on public transit yields insight into the flows of affects and their relation to power. Vaska notes that when wealthy people and men take up space, they arouse little anger or disdain, inviting instead affirmation, respect, and support, making explicit that comfort is available to those who can afford it and to those who feel entitled to it:

"And it turns out rich people are allowed to be fat. And it turns out that the chairs in first class don't cut into my hips... in first class, it's a lot more comfortable. [Men] are allowed to be big. I remember-I have a friend who's about to be taking a plane ride, and she hasn't taken a plane ride in a long time. And she's anticipating fatphobia, and at one point-you know, she's significantly larger than an airplane seat. But I said to her, if you were a dude, people would be falling all over themselves trying to make you more comfortable, but because you're a woman, they think you're somehow failing at invisibility."

The gendering of space on public transit is captured here when Vaska juxtaposes masculinist practices of taking up space against her and her friend's felt pressures to contort their bodies. Compare cis male entitlement to space to Vaska's experiences, who describes accepting extreme discomfort for the sake of avoiding fatmisia.

\section{WHILE EXERCISING}


One of the central sites for the circulation and performance of fatmisia is organized physical activity in spaces like public schools or private gyms. In private gyms especially, Schvey and colleagues note that fat members are particularly prone to weight stigma, the consequences of which include "negative attitudes toward the gym, maladaptive coping behaviors, weight bias internalization, unhealthy weight control practices, and poorer self-reported physical and emotional health" (cited in Ebbeck \& Austin, 2018, p. 82). The logic that sustains fatmisia in exercise contexts is that fat bodies are constructed as always already out of place while exercising-a contradiction in terms. Fat bodies are coded as inactive in the fatphobic imagination, a code that situates active thin bodies legitimately in place. Fatmisia functions to maintain the physical boundaries of fitness spaces, excluding fat bodies through both overt violence that discourages their entrance, and the messaging and logics that assume fat to be a consequence of inactivity and immoral health choices. Anti-fat discourses claim that if fat bodies knew how to exercise legitimately, they would already be thin. Exercise facilities, then, take on a double purpose: they function both to exclude and to prevent the existence of fat bodies.

The spatialization of inclusion and exclusion in our data cannot be divorced from the settler colonial context in which this research was conducted. Settler colonialism, as a socio-political and economic system of racialized violence, is organized around the appropriation of space and the naturalization of the violence that enables appropriation to take place (Green, 2014). Within our mapping of fatmisia in exercise spaces, we encounter dynamics that signal long-standing traditions of place-making in Canada that rely on discourses of cultural annihilation in the interests of self-improvement in order for marginalized bodies to find themselves in place.

The spatialized logic at stake in exercise facilities maintains that fat bodies belong only if they are atoning for their size by actively working to reduce it. Fatmisia circulates in fitness spaces to limit the social participation of fat bodies to a temporary role as bodies-in-transition. Fat bodies are imagined to be 
shrinkable, and once they become thin, their belonging within the space of the gym will no longer be contingent. Weight-loss messaging, the presence of medical grade scales, personal training questionnaires that require the declaration of a "fitness goal" or "goal weight," combined with ritualized body measurement practices, collude to structure the space of organized fitness as a site of aspirational thinness. Within fitness spaces, fat bodies are prevented from social participation. Consequently, participants describe ongoing internal conflicts as they confront fatmisia in gyms. Exercising for exercise's sake is impossible in the face of persistent fatmisia. As Emery, a cis femme queer white woman says, "it's like a constant struggle to keep it being about [exercise] and not being about anxiety about losing weight. ...I feel so awkward. And I feel very out of place. And uneasy. And I don't want to be there because I want to lose weight." For Emery, her out-ofplace-ness is matched by internal conflicts about the reason behind the impulse to exercise. She offers:

"It's much more an internal dialogue and it's much more a struggle within myself like 'Am I really here-I don't want to be-am I here because I'm unhappy with my body, because that feels shitty. Am I here because I'm happy with my body and feel good moving in it? That feels good.' And then l'll be like 'I don't want to do that anymore. I's making me feel shitty about myself,' so l'll stop going to the gym for months."

The net result for Emery is that, because of the weight-loss messaging, alongside spatial mechanisms that exclude non-normative bodies, she simply does not go to the gym. Her recurring feeling that she does not "fit in" at the gym speaks to the power of fatmisia as a place-making device, rendering gyms as sites of curated participation and overt exclusion.

Exercise as the exclusive purview of thin bodies is a recurring theme for many participants. Leigh describes being singled out in elementary school by a teacher who anticipated her inability to complete an activity in Physical Education (PE) class: 
"When I was in um, grade $5 .$. we had a PE class, and they were doing like, a big run around the parking lot and the school. ...And I remember we had a new gym teacher. ...He said in front of the whole class, which was about 25 or 30 kids, 'I want everyone to do this run except for [participant] and [friend]'—who was also fat-'They can walk.' And I was like, 'Why are you saying that we can walk when everyone else has to run?' And in front of the whole class he was like, 'I know you won't be able to run the whole way. Because you're obese.' In front of the whole class. And I just wanted to die."

Leigh's anecdote points to fatmisia as a tool of distinction and exclusion. Her body was singled out from the class as abnormal and incapable. Her teacher used the pathologizing term 'obese' to describe her, justifying his exclusion of her public participation under the banner of health. Further, Leigh notes, "I remember feeling so ashamed that I was stopping and walking, but then, kids all around me were stopping and walking, because it was such a long run to ask kids to do in the first place!" Therefore, Leigh was excluded not only from full social participation, but also from having her exhaustion normalized. Leigh's need to walk was not interpreted as a result of the assignment being unattainable, but rather because of her size, whereas other classmates were able to not have their exhaustion pathologized. Canadian schools have a long history of enacting violence on the bodies of students, particularly using phenotypic distinction as a method for naturalizing violences on the basis of race, indigeneity, gender, disability, and fat (Rice, 2007, 2014). Imposing a standardized physical requirement on students and then labelling those who fail to meet it as unworthy is a productive act, producing and inciting feelings of shame, loneliness, and self-hatred.

The index of hatred here is reflected in Leigh's reaction to her teacher's words: she wanted to die. Here fatmisia materializes as shame in Leigh for being constructed as different, despite the fact that her classmates were just as exhausted from the exercise as she was. The teacher's assumptions about Leigh's 
physical stamina indicated an interest in erasing fat life. Leigh's reaction-wanting to die-points to its operation, and highlights its goal: fat death.

\section{CONCLUSION}

We sought to map how fatmisia encompasses a constellation of emotions, among them fear, revulsion, disgust, and disdain. Fat hatred was also shown to materialize in a range of expressions, including presumptuous advice, disapproving gestures, open humiliation, and violent words and acts. The frequency and intensity of participants' experience of hatred was contingent and compounded, hatred against fat tangled in hatred against myriad other body markers, including race, indigeneity, gender, gender identity and expression, ability, and class. What holds together these experiences is the driving purpose to the affect, for fat hatred can be shown in all these instances to organize subjects and spaces with the purpose of excluding, expunging, and ending non-normative living entangled with fatness.

The impacts of such an economy of fat hatred, arranged and directed in assemblage with other forms of hatred, are borne out on the hated. Our interview participants recount internalizing anxiety and shame, feeling out of place and like they do not belong, and avoiding public engagement and open confrontation at the risk of their own personal isolation or discomfort. We committed to presenting their experiences as accounts of hatred-so in the strongest possible terms-in order to flag how serious, how visceral, the negative feelings about fat circulating in public space can be, and how deeply those feelings impact their intended targets.

\section{REFERENCES}

Ahmed, S. (2001). The Organization of Hate. Law \& Critique, 12, 345-365.

Ahmed, S. (2004). The Cultural Politics of Emotion. New York: Routledge.

Ahmed, S. (2010). Happy objects. In M. Gregg \& G.J. Seigworth (Eds.), The Affect Theory 
Reader (pp. 29-51). Durham: Duke University Press.

Ahmed, S. (2017). Living a Feminist Life. Durham: Duke University Press.

Bacon, L. \& Aphramor, L. (2011). Weight Science: Evaluating the Evidence for a Paradigm Shift. Nutrition Journal, 10(9).

Bahra, R.A. (2018). "You can only be happy if you're thin!" normalcy, happiness, and the lacking body. Fat Studies, 7(2), 193-202.

Braun, V. \& Clarke, V. (2006). Using thematic analysis in psychology. Qualitative Research in Psychology, 3, 77-101.

Cooper, C. (2016). Fat Activism: A Radical Social Movement. Bristol: HammerOn Press.

Crenshaw, K. (1989). Demarginalizing the intersection of race and sex: A black feminist critique of antidiscrimination doctrine, feminist theory and antiracist politics. University of Chicago Legal Forum, 139-167.

Deleuze, G. \& Guattari, F. (1988). A thousand plateaus. B. Massumi, trans. Minneapolis: University of Minnesota Press.

Ebbeck, V., \& Austin, S. (2018). Burning off the fat oppression: Self-compassion exercises for personal trainers. Fat Studies, 7(1), 81-92.

Fee, M. (2006). Racializing narratives: obesity, diabetes and the "Aboriginal" thrifty genotype. Social science \& medicine, 62(12), 2988-2997. 
Gaesser, G. (2009). Is "Permanent Weight Loss" an Oxymoron? The Statistics on Weight Loss and the National Weight Control Registry. In E. Rothblum \& S. Solovay (Eds.), The Fat Studies Reader (pp. 37-41). New York: New York University Press.

Gailey, J. (2014). The Hyper(in)visible Fat Woman: Weight \& Gender Discourse in Contemporary Society. Basingstoke: Palgrave Macmillan.

Green, J. (2014). From Colonialism to Reconciliation Through Indigenous Human Rights. In J. Green (Ed.), Indivisible: Indigenous Human Rights (pp. 18-42). Halifax: Fernwood.

Guattari, F. (1996). The Guattari Reader. G. Genosko (Ed.). London: Blackwell.

Massumi, B. (2002). Parables for the Virtual: Movement, Affect, Sensation. Durham: Duke University Press.

McPhail, D. (2016). Indigenous People's Clinical Encounters with Obesity: A Conversation with Barry Lavallee. In J. Ellison, D. McPhail, \& W. Mitchinson (Eds.), Obesity in Canada: Critical Perspectives (pp. 175-185). Toronto: University of Toronto Press.

Opotow, S. \& McClelland, S.I. (2007). The Intensification of Hating: A Theory. Social Justice Research, 20(1), 69-84.

Poudrier, J. (2007). The geneticization of Aboriginal diabetes and obesity: Adding another scene to the story of the thrifty gene. Canadian Review of Sociology, 44(2), 237-261.

Puar, J.K. (2007). Terrorist Assemblages: Homonationalism in Queer Times. Durham: Duke University Press.

Puar, J.K. (2012). "I would rather be a cyborg than a goddess": Becoming-intersectional in assemblage theory. PhiloSOPHIA 2(1): 49-66.

Puwar, N. (2004). Space Invaders: Race, Gender and Bodies out of Place. Oxford: Berg. 
Rail, G. \& Jette, S. (2015). Reflections on biopedagogies and/of public health: On bio-others, rescue missions, and social justice. Cultural Studies $\leftrightarrow$ Critical Methodologies, 15(5), 327-336.

Razack, S.H. (2015). Dying from Improvement: Inquests and Inquiries into Indigenous Deaths

in Custody. Toronto: University of Toronto Press.

Rice, C. (2015). Rethinking Fat: From Bio- to Body-Becoming Pedagogies. Cultural Studies $\leftrightarrow$ Critical Methodologies, 15(5), 387-397.

Rice, C., Pendleton Jiménez, K., Harrison, E., Robinson, M., Rinaldi, J., LaMarre, A., \& Andrew, J. (forthcoming). Bodies at the Intersection: Reconfiguring Intersectionality through Queer Women's Complex Embodiments. Signs: A Journal of Women in Culture and Society.

Rice, C. (2007). Becoming the fat girl: Emergence of an unfit identity. Women's Studies International Forum, 30(2), $158-174$.

Rice, C., (2014). Becoming Women: The Embodied Self in Image Culture. Toronto: UT Press.

Rinaldi, J., Rice, C., LaMarre, A., McPhail, D., \& Harrison, E. (2017). Fatness and Failing Citizenship. Somatechnics, 7(2), 218-233.

Robison, J. (2015). The "Last man standing" fallacy or why lt's not nice to play with denominators. Fat Studies, 4(2), 208-211.

Rothblum, E.D. (2018). Slim Chance for Permanent Weight Loss. Archives of Scientific Psychology, 6, 6369.

Seigworth, G.J., \& Gregg, M. (2010). An Inventory of Shimmers. In M. Gregg \& G.J. Seigworth (Eds.), The Affect Theory Reader (pp. 1-28). Durham: Duke University Press. 
Zembylas, M. (2007). The Affective Politics of Hatred: Implications for Education. Intercultural Education, 18(3), 177-192. 